\title{
The Development and Initial Validation of a Career Calling \\ Scale for Emerging Adults
}

\author{
Anna Praskova, Peter Creed, and Michelle Hood \\ School of Applied Psychology and Menzies Health Institute Queensland \\ Griffith University, Australia
}

Contact: Prof Peter Creed, p.creed@griffith.edu.au

\section{PAPER CAN BE CITED AS:}

Praskova, A., Creed, P. A., \& Hood, M. (2015). The development and initial validation of a career calling scale for emerging adults. Journal of Career Assessment, 23, 91-106. doi:10.1177/1069072714523089 


\begin{abstract}
Career calling, a salient career goal that is personally meaningful and oriented towards helping others, is a developmental construct that is especially important for emerging adults when making career decisions and setting career goals. As no existing measure reflects the developmental aspect of career calling, we devised an age-appropriate measure suitable for use with this population. We reviewed the extant literature, conducted focus groups, and used expert reviews to generate 34 initial items. Item and exploratory factor analyses were employed to reduce these items to 15, representing three reliable subscales (Study 1; $N=345$ emerging adults). Confirmatory factor analysis supported the initial factor structure (Study 2; $N=527)$. Expected correlations with adult measures of career calling (search and presence), general career indecision, and life satisfaction supported construct validity (Study 2; $N=$ 435). The implications for research and practice are discussed.
\end{abstract}

Keywords: career calling; emerging adults; career goal-setting; personal meaning; otheroriented meaning; goal engagement; career development 


\section{The Development and Initial Validation of a Career Calling Scale for Emerging Adults}

The construct of career calling has received increased attention in recent years. There is a greater interest in understanding why people are searching for more meaningful ways to engage with work (Weiss, Skelley, Haughey, \& Hall, 2004), how they deal with concerns in the areas of career development and satisfaction, and how these concerns relate to personal well-being and growth (Elangovan, Pinder, \& McLean, 2010; Hall \& Chandler, 2005; Wrzesniewski, McCauley, Rozin, \& Schwartz, 1997). To date, however, there is no universal agreement over the definition, origins, or developmental trajectory of career calling (Elangovan et al., 2010; Hall \& Chandler, 2005; Wrzesniewski, 2012). Generally, it is agreed that adults with a calling approach their work with a stronger sense of meaning, purpose, and fulfilment, and have a greater desire to contribute to others and the community through their occupational activities (Dik \& Duffy, 2009; Hall \& Chandler, 2005; Steger, Pickering, Shin, \& Dik, 2010). This understanding has guided the development of several career calling measures, although not all of these measures have strong theoretical underpinnings, are not assessing developmental progress towards a future career, focus mainly on those in the workforce, or need further investigation to confirm their psychometric properties (Duffy, Bott, Allan, Torrey, \& Dik, 2012; Duffy \& Sedlacek, 2007; Rosso, Dekas, \& Wrzesniewski, 2010). Importantly, there are no scales developed specifically to assess career calling in emerging adults, whose main developmental focus is on their future career. This study reports on the development and initial validation of a scale to meet this purpose.

\section{The Career Calling Construct}

The concept of career calling has a long history in Western culture. Early conceptualisations considered it as a specific request from God for someone to fulfil a particular task or role (Colozzi \& Colozzi, 2000). Later, the construct was secularised and 
modified to include an emphasis on an active search for personal and professional development (Hall \& Chandler, 2005; Weiss et al., 2004). Today, religious callings generally refer to missions to serve others (Dalton, 2001; Hernandez, Foley, \& Beitin, 2011); whereas other traditional, non-secular definitions stress that a calling can arise from any identifiable, external source (e.g., God, family legacy; Dik \& Duffy, 2009) or come from an unknown “push” to the "right place” (Bunderson \& Thomson, 2009, p. 38). Most of these perspectives agree that callings are pro-social and altruistic (e.g., Dik \& Duffy, 2009; Hunter, Dik, \& Banning, 2010), depict a sense of meaningfulness and mission (Dik \& Duffy, 2009), involve matching with and utilising one’s gifts, interests, talents, and opportunities, include drawing on socially significant values and goals, and result in enhanced eudemonic well-being (Bunderson \& Thompson, 2009; Hagmaier \& Abele, 2012; Hardy, 1990; Hunter et al., 2010; Steger et al., 2010).

Secular callings are considered to originate within the individual (Hall \& Chandler, 2005; Rosso et al., 2010; Wrzesniewski, Dekas, \& Rosso, 2009), and be central to one’s identity and unique talents (Dobrow, 2007; Hall \& Chandler, 2005; Novak, 1996). These perspectives recognise people's efforts to find a sense of personal, self-relevant meaning (Bellah, Madsen, Sullivan, Swidler, \& Tipton, 1985; Dobrow, 2004), which can apply to people of any faith, or none (Dobrow, 2007), and can reflect a desire to contribute to the community or larger society in some way (Dobrow, 2004; Elangovan et al., 2010; Steger et al., 2010). Individuals can understand their callings as a consuming passion towards a specific domain, which can generate a strong sense of urgency, longevity, and domainspecific competence (Dobrow, 2004, 2007; Dobrow \& Tosti-Kharas, 2011), personal mission or a quest for self-fulfilment and enjoyment (Dobrow, 2004; Hall \& Chandler, 2005; Novak, 1996), or a work orientation, where work is considered inseparable from one's life (Bellah et al., 1986; Wrzesniewski et al., 1997). 
Rather than seeing calling as something stable in the individual (Dobrow, 2004), Hall and Chandler (2005) argued that, next to a strong sense of purpose, individuals with a calling needed to be internally driven by their own values and identity, motivated to follow a path (i.e., be self-directed), and be self-exploring, adaptive, and confident in manoeuvring in the career terrain. This view highlights the ongoing processes of goal-setting, goal-pursuit, adaptation, and development in a calling. In other words, the development and achievement of a calling involves personal agency, or an orientation that is goal- and action-orientated, and includes self-motivational and adaptive processes necessary to reach one's goals (Bandura, 1991; Elangovan et al., 2010). In the careers’ area, adaptive processes include career exploration, introspection, reflection, and relational activities, such as discussions with parents and friends (Hall \& Chandler, 2005).

Career calling has been distinguished from passion (Vallerand et al., 2003), flow (Csikszentmihalyi, 1990), and work engagement (Kahn, 1990). These constructs are considered to exist on an episodic basis, rather than to be more enduring, stable, and longterm, which characterizes a calling (Dik \& Duffy, 2009; Dobrow \& Tosti-Kharas, 2011; Elangovan et al., 2010; Hall \& Chandler, 2005). It has also been differentiated from other work constructs, such as work commitment (Loscocco, 1989), career salience (Greenhaus, 1971), and career hope (Diemer \& Blustein, 2007), which do not capture the core meaningfulness, purpose, and pro-social components of calling. Last, some concepts focus on a narrow aspect of calling, but do not capture its full, complex nature. For example, career identity, protean career orientation, and work preference are considered important career constructs, but they do not encompass all components of a calling (Amabile, Hill, Hennessey, \& Tighe, 1994; Dobrow, 2004; Hall \& Chandler, 2005).

\section{Career Calling and Emerging Adults}

Emerging adulthood is the transition period from adolescence to early adulthood (i.e., 
approximately 18 to 25 years; Arnett, 2000). During this period, existing goals come to an end and new more salient goals regarding study, career, and family life relevant to adulthood are developed and become the main focus (Havighurst, 1953/1961). Appraising goals in these areas as important and controllable, and establishing plans and actions to achieve them, can be used as markers of positive development and adaptation for this age group, and can translate into positive outcomes for current well-being and future functioning (Shulman \& Nurmi, 2010). Developing a career calling reflects conscious and unconscious processes around goal setting and goal pursuit (Bandura, 1991; Locke \& Latham, 1990); that is, career calling becomes salient for emerging adults as they formulate their career goals and engage in preparatory career actions that are focused on achieving meaningful work as an adult (Berg, Grant, \& Johnson, 2010; Duffy \& Sedlacek, 2010; Hall \& Chandler, 2005; Nurmi, 1993). From this perspective, a career calling reflects goals that are higher-order, more abstract, and have a longer term perspective, in contrast to lower-level, more concrete, and short-term goals, which are the means by which higher-order goals are achieved (Lord, Diefendorff, Schmidt, \& Hall, 2010).

Consistent with this view, career calling is increasingly regarded as a developmental and dynamic construct (Elangovan et al., 2010; Weiss et al., 2004), which begins before one enters the workplace and strengthens as one matures (Wrzesniewski, 2012). Thus, the manifestation of career calling in emerging adults, who have not yet formally entered the workforce and who are still developing and deciding on a future direction, will differ from that of adults who have decided on their career directions and who have entered the workforce. Based on this developmental and goal-setting perspective (Bandura, 1991; Havighurst, 1953/1961; Locke \& Latham, 1990), career calling in emerging adulthood can be represented as a mostly self-set, salient, higher-order, career goal, which generates meaning and purpose for the individual, and which has the potential to be strengthened (or weakened) 
by engaging in goal-directed, career-preparatory actions and adaptive processes aimed at meeting this goal. This definition is consistent with other conceptualisations that view calling as a context-specific goal (Duffy \& Dik, 2013) and promote personal agency as the means for successfully pursuing it (Elangovan et al., 2010; Hall \& Chandler, 2005; Dobrow, 2004).

\section{Research on Calling in Emerging Adults}

In terms of prevalence, career calling is a salient construct for more than $40 \%$ of university (Duffy \& Sedlacek, 2010) and first year medical students (Burges, Manuel, \& Duffy, 2013), which is similar to rates found in adults (Bunderson \& Thompson, 2009; Wrzesniewski et al., 1997). Career calling is associated with more life and academic satisfaction in university students (Duffy, Allan, \& Dik, 2011; Duffy, Allan et al., 2012). Additionally, those with a higher career calling show better adjustment and more positive career attitudes (Steger et al., 2010), greater engagement in career-related activities (Hirschi, 2011), and more career planning (Hirschi \& Herman, 2013). They have more career insight, are more decided and comfortable about their career choice (Dobrow \& Tosti-Kharas, 2011; Duffy \& Sedlacek, 2007), have higher career expectations (Dik, Sargent, \& Steger, 2008), and more confidence and motivation to pursue their career (Dobrow \& Tosti-Kharas, 2011; Hirshi, 2011). Longitudinal relationships with career calling, however, are less clear. Dobrow and Tosti-Kharas $(2011,2012)$ found calling to be associated with later career satisfaction and more career-related behaviors, while Duffy, Manuel, Borges, and Bott (2011) found no causal relationship over time between calling and career development or life meaning, and Hirschi and Hermann (2013) found bidirectional associations with career planning and selfefficacy.

\section{Existing Measures of Calling}

Both the traditional and secular perspectives on calling have guided the development of career calling measures, although no measure incorporates both viewpoints. Existing 
measures also have differing assessment foci (e.g., assessing the presence of, search for, experiences with, orientations for, and currently living, a calling), and not all measures have demonstrated adequate reliability and validity or have employed a sound theoretical framework, suggesting the need for more work on measurement development (Wrzesniewski, 2012). Dik, Eldridge, Steger, and Duffy (2012) devised two calling scales: (a) the 4-item Brief Calling Scale, which has two, 2-item subscales (presence of a calling and search for a calling), and (b) the 24-item Calling and Vocation Questionnaire. While both are useful, 2item subscales cannot capture the complexities of the construct, and the longer measure is limited by focusing on those in employment (e.g., "My work contributes to the common good”). Other calling scales which focus on or have items aimed at those in the workforce include the 6-item Living One’s Calling scale (Duffy, Allan, \& Bott, 2012; e.g., "I am living out my calling right now in my job”); the Neoclassical Calling Questionnaire (Bunderson \& Thompson, 2009), which contains a 6-item context-specific subscale (for zookeepers; e.g., "I was meant to work with animals”) and a 6-item context-free subscale (for Masters students; e.g., "I was meant to do the work I do”); and the 9-item Multidimensional Measure of Calling (Hagmaier \& Abele, 2012; e.g., “I am passionate about doing my job”).

A further limitation is that many existing measures are unidimensional, whereas career calling is a multi-dimensional construct. Examples here include the eight calling items from the 18-item University of Pennsylvania Work-Life Questionnaire (Wrzesniewski et al., 1997); the Neoclassical Calling Questionnaire (Bunderson \& Thompson, 2009), whose items predominantly reflect work as a passion; and Dobrow and Tosti-Kharas’s (2011) 12-item scale that assesses multiple domains (e.g., passion, identity, urgency), but is considered unidimensional. Only two multidimensional scales were identified. First, the Calling and Vocation Questionnaire (Dik et al., 2012) includes six subscales and two composite scales (i.e., presence and search for a calling). However, the six subscales do not reflect the original 
hypothesised domains, include some items that are more suitable to those in employment (e.g., "My work helps me live out my life’s purpose”), and several of the six factors account for little overall variance (i.e., < 5\%). Second, the Multidimensional Measure of Calling (Hagmaier \& Abele, 2012) taps three domains (identification with one’s work and personenvironmental fit, sense and meaning and value-driven behavior, and transcendent guiding force; 3 items each). However, this is designed for adults in work already.

A final limitation of existing measures is that few utilise a language that addresses the perspective of a developing calling, which is appropriate for young and emerging adults who have not yet entered the full-time workforce or who have not yet settled into employment that reflects their calling (Sharf, 2006). Developing a career calling during late adolescence/early adulthood involves complex exploratory behaviors and a willingness to experiment and engage in activities that have the potential to develop into a calling (Elangovan et al., 2010). This process goes hand-in-hand with other career and life preparatory behaviors, such as educational planning and developing relationship skills (Arnett, 2000; Hall \& Chandler, 2005; Havighurst, 1953/1961), all of which have the potential to bring a sense of purpose and meaning (Berg et al., 2010).

\section{The Present Study}

The development of a career calling scale for emerging adults needs to be based on a conceptualization that integrates existing understandings of a calling that are relevant to the developmental tasks that emerging adults must master. This conceptualization needs to recognise both self- and other-oriented purpose and meaning derived from the calling, and recognise that a calling might originate internally (e.g., from abilities and values) or externally (e.g., from opportunity, family, destiny). We report on two studies. In Study 1, we developed a new, multi-dimensional scale of career calling for emerging adults and tested its factor structure using item analysis and exploratory factor analysis. In Study 2, we confirmed 
the factor structure of this new scale, and tested for criterion-related, convergent, and discriminant validity by correlating it with existing measures identified in the literature on career calling and goal-setting.

\section{Study 1: Scale Development}

\section{Method}

Item Development. Items for the new career calling scale were generated to reflect the goal-directed nature of career development in emerging adults. To inform this process, we first reviewed the literature on career calling as it applied to emerging adults, and second, conducted four focus groups with emerging adults (each $N=12$; approximately $50 \%$ male/female mix) to explore how career calling was manifested in this population. Focus group participants were recruited from the authors' university (2 groups) and from a technical college (2 groups) located in the same city. Ethical clearance was obtained, the research was advertised via course webpages (university) and class circulars (college), and the focus groups were conducted on the students' campuses. Participants were asked to brainstorm the key aspects of career calling as they understood it, including experiences and manifestations associated with having and not having a calling. On top of this, we wanted to validate the key dimensions of the construct that we identified in the literature, and identify any additional content areas relevant to emerging adults (Vogt, King, \& King, 2004).The focus groups were audiotaped, transcribed, and used as a reference for the development of the items.

A content analysis of the career calling construct derived from the literature review and the focus groups identified three elements of career calling important to this age group. First was personal meaning, which covers aspects of calling that acknowledge career choice as a fit with one's personal values and identity (i.e., is important to the self, is intrinsically rewarding, and generates satisfaction). Second, other-oriented meaning covered aspects related to helping and altruistic behaviors (i.e., engagement in socially significant goals, 
contributing to the community, and sense of satisfaction from helping others). The third domain was active engagement, which reflected the action orientation in pursuit of a calling (i.e., pursuing interests and competencies, having a quest for fulfilment and enjoyment, being driven by an inner urge or passion). To ensure a broad coverage for the three career calling dimensions, we identified items that reflected behavioral, cognitive, and affective manifestations of each domain (e.g., "I do things [volunteer, read, scan the internet] just to find out more about my dream career” reflects a behavioral manifestation of the selfdirectedness dimension). Our goal was to develop a scale of approximately 15 items to minimise respondent's fatigue or response bias, while assuring sufficient content coverage (Hinkin, 1998).

Sixty-two items were written initially, including both negatively and positively worded items (Hinkin, 1998). These items were then reviewed by six independent experts from the career development and test construction areas. The experts rated how adequately each item represented the given domain, commented on the item phrasing, readability, response format (6-point Likert-like scale with endpoints of $1=$ strongly disagree and $6=$ strongly agree), and instructions. Based on their ratings ( $0=$ not at all adequate; $4=$ very adequate), 52 items with a content validity index of $\geq .83$ (i.e., five out of six experts rated the item as adequate or better; Lynn, 1985) were retained. As Hinkin (1998) recommended that at least twice as many items than is required for the final scale should be administered in a survey, we removed a further 18 items that were complex or redundant, which left 34 items that we considered best represented the domains and manifestations of a career calling.

After testing the items for readability (Flesch Reading Ease = 39.1; Flesch-Kincaid Grade Level = 8.4), the 34 items, together with demographic questions about age, gender, academic achievement, working situation, and study program were compiled in a questionnaire and administered to a sample of emerging adults. 
Participants. Participants were 345 emerging adults (62.9\% female, mean age $=$ 20.72, $S D=2.49$; range 17 - 25 years). Their self-reported mean academic achievement level in the final year at high school ("What grade did you typically receive in your final year at high school?”) was $1.99(S D=0.72)$ on a 5-point scale ranging from $1=$ very high achievement to 5 = very limited achievement. Participants were working (66.2\%) or nonworking (30.2 \%) university (degree programs of health, business, arts, design, media, law, science, education, and engineering) or technical college students (vocational certificates and diplomas for cookery, retail, and electrician) and a small group of young adults (3.6\%) who were in the labour force, either working or seeking employment. All were recruited from a large regional city on the east coast of Australia, and consistent with the composition of the Australian population, the vast majority was English-speaking Caucasian.

Procedure. The study was conducted with the approval of the authors' university ethics committee. The questionnaire was administered using both online and paper-andpencil format. University students were invited to complete an online survey that was advertised via a university-wide email, which was distributed to all staff and students. The technical college students were invited to complete a paper survey as the college was not able to disseminate information via email. These surveys were distributed by college staff and returned to the researchers in a sealed envelope. Labour force participants were young people engaged by, or on placement to, the university, who completed the online survey. All participants were able to enter a prize draw for a \$50 shopping voucher.

\section{Results}

First, we assessed item distributions, checked if there were any items with floor or ceiling effects, and tested for excessively high inter-item $(r \geq .80)$ or low item-total correlations $(r \leq .30)$. No items were deleted as a result of these procedures. Second, we used exploratory (principal-axis) factor analysis to determine the underlying factorial structure and 
identify items for removal. We selected a direct oblimin rotation as we expected the domains to correlate to represent an overall career calling measure (Hair, Black, Babin, \& Anderson, 2010). The Kaiser-Meyer-Olkin measure of sampling adequacy (.95) and Bartlett’s test of sphericity $(p<.001)$ for the initial analysis indicated that the 34 items were suitable for factor analysis. Decisions regarding the number of factors to be retained were guided by the scree plot (Hinkin, 1998), Velicer’s minimum average partial test, parallel analysis (O’Connor, 2000), having more than three items in a factor (Costello \& Osborne, 2005), and factorial meaningfulness (Hinkin, 1998).

The first analysis indicated five factors with eigenvalues greater than 1 . However, the scree plot, Velicer's minimum average partial test, and the parallel analysis suggested a 3factor solution. Being consistent with our expected three domains of a calling, we accepted the 3-factor solution and removed four items that loaded strongly on the two weaker factors. Subsequent to this, items were deleted if their factor loadings were $<.40$, or they showed cross-loading on other factors ( $\geq .30$; Costello \& Osborne, 2005). These procedures left us with 15 items that accounted for $62.93 \%$ of the variance, exceeding the recommended minimum target of 60\% (Hinkin, 1998). All items showed acceptable item-total correlations ranging from .50 to .71, and communality values > .40 (Costello \& Osborne, 2005). Factor 1, which contained five "other-oriented meaning" items $(\alpha=.86)$ accounted for $41 \%$ of the variance. Factor 2, which contained five "personal meaning" items $(\alpha=.80)$ accounted for $12 \%$, and Factor 3, with five “active engagement” items $(\alpha=.82)$ accounted for $9.93 \%$ of the variance. Inter-factor correlations ranged from .37 to .58. The internal reliability coefficient for the 15 items was $.88(M=67.08, S D=10.87$; range $=37$ to 90$)$. See Table 1 for factor loadings and eigenvalues.

\section{Discussion}


We used standard scale development procedures to develop a 15-item scale suitable to assess career calling in emerging adults. This included integration of the career calling, developmental, and goal-setting literature; use of focus groups that identified how career calling was relevant to, and how it manifests itself in, emerging adults; and expert ratings of items, all of which supported content validity. Consistent with our initial proposition, three subscales were identified. The other-oriented meaning subscale reflected a calling associated with a future career that would benefit others and contribute to the community. Personal meaning reflected a calling associated with a future career that would be personally rewarding. Active engagement reflected enthusiasm and inspiration associated with pursuing the calling. All of the subscales added meaningful variance to the overall construct and showed moderate correlations with one another, indicating that while explaining some common variance, they assessed largely independent aspects of career calling. This was expected, as meaningfulness and purpose, for example, are related concepts, but are not considered identical. The independence of the three subscales was supported by the exploratory factor analysis and the good internal reliability for each one (coefficients of .80 or better). In support of initial construct validity for the full scale, all item-total correlations were in the range of .50 to .71, and the internal reliability for the full scale was good.

The next step was to confirm the factor structure of the scale and assess the construct validity against other constructs in the nomological net. To do this, we collected data on a second sample of emerging adults, assessed the factor structure using confirmatory factor analysis, and tested the correlates of the scale against existing scales of presence and search for calling, life satisfaction, and career indecision.

\section{Study 2: Confirmatory Factor Analysis and Construct Validity}

\section{Method}

Participants and Procedure. Participants were 527 emerging adults (53.5\% female; 
mean age $=19.87$ years, $S D=2.37$; range $=17$ to 25 ). Their mean final high school year academic achievement score was $1.96(S D=0.68)$. The majority were working $(64.2 \%)$ or non-working (32.7\%) students, enrolled in university (64.9\%) or technical vocational programs; the remainder (3.1\%) were working or seeking employment. We used the same recruitment methods, survey options, and incentives as for Study 1.

\section{Materials.}

Career Calling. We used two scales to assess career calling. The first was the 15-item career calling scale developed in Study 1. The response format was a 6-point Likert-like scale with endpoints of $1=$ strongly disagree and $6=$ strongly agree. The internal reliability coefficients with this sample were .89 (full scale), .85 (other-oriented subscale), .80 (personal meaning subscale), and .81 (active engagement).

The second was the 4-item Brief Calling Scale (Dik et al., 2012), which was used to assess the presence of (2 items; e.g., "I have a calling to a particular kind of work”) and the search for calling (2 items; e.g., "I am trying to figure out my calling in my career”). Responses were given on a 6-point scale with anchors of $1=$ absolutely untrue of me and $6=$ absolutely true of me. Duffy and Sedlacek (2007, 2010) reported correlations between the subscale items of $>.80$ (presence) and $>.70$ (search), and correlations in the predicted direction with career development progress, well-being, and life meaning in university students. The inter-item correlations for our sample were .83 (presence) and .79 (search).

Well-being. We used the 5-item Satisfaction with Life Scale (Diener, Emmons, Larsen, \& Griffin, 1985) to assess general life satisfaction. Participants responded on a 6point Likert scale with anchors of $1=$ strongly disagree and $6=$ strongly agree. A sample item was “I'm satisfied with my life”. This scale has demonstrated good psychometric properties with undergraduate students, including an internal reliability coefficient of .87, a 2- 
month test-retest reliability of .82, and correlations with other scales in the expected direction (Diener et al., 1985). The internal reliability coefficient for our sample was .88.

Career Indecision. We used the top 10 loading items of the 22-item Indecisiveness Scale (Germeijs \& De Boeck, 2002) and adapted them to reflect career decisions by adding “career” to the scale items. Participants responded on a 6-point Likert-like scale with anchors of 1 = strongly disagree and 6 = strongly agree (e.g., "I often reconsider my career decision”). An internal consistency coefficient for the full scale of .91 was reported in senior high school students. Higher scores on this scale were associated with lower self-esteem, less awareness about the need to make career decisions, less career exploration, and less commitment to study (Germeijs \& Boeck, 2002; Germeijs, Verschueren, \& Soenens, 2006). We conducted a confirmatory factor analysis on the ten items used and identified a 1-factor solution. In support of construct validity, the 10 -item scale was associated with other scales in our study in the expected directions (e.g., associated negatively with career calling), and the reliability coefficient was sound at .87 .

\section{Results}

Factor Structure. We used confirmatory factor analysis (AMOS Version 21) to validate the factor structure of the 15-item career calling scale. We tested two models: (a) a one-factor model, where all items were allowed to load on a single latent variable of career calling, and (b) a higher-order factor model, where the three factors identified in the exploratory factor analysis were allowed to load on a second-order factor of career calling. We followed Hair et al.’s (2010) recommendations for a sample $\geq 250$ participants with $>12$ observed variables, and assessed model fit using Chi-square $\left(\chi^{2}\right.$; significant $p$ value expected), the Comparative Fit Index (CFI > .92 expected), the Tucker-Lewis Index (TLI > .92), the Goodness of Fit Index (GFI > .90), the Root Mean-Square Error of Approximation (RMSEA < .07), and the Standardized Root Mean-Square Residual $(\mathrm{SRMR} \leq .08)$. The 
Normed Chi-square $\left(\chi^{2} / d f\right)$ was also calculated as $\chi^{2}$ is sensitive to sample size. A ratio of 3:1 or less suggests a good fit.

In the first model, we allowed all 15 items to load freely on a single latent variable of career calling as a means to assess if the items could be represented as a unidimensional scale. The analysis yielded unsatisfactory fit statistics: $\chi^{2}(90)=1008.80, p<.001, \chi^{2} / d f=$ 11.21, GFI $=.75$, SRMR $=.09, \mathrm{CFI}=.73, \mathrm{TLI}=.69$, and RMSEA $=.14$. The second analysis assessed the 15 items as three separate factors, which were allowed to load onto a secondorder factor. This model assessed (a) if the three factors identified in Study 1 could represent the 15 items, and (b) if a second-order factor of career calling could represent the three firstorder factors of other-oriented meaning, personal meaning, and active engagement (Hair et al., 2010). The fit statistics for this model were good: $\chi^{2}(84)=237.88, p<.001, \chi^{2} / d f=2.83$, $\mathrm{GFI}=.95, \mathrm{SRMR}=.05, \mathrm{CFI}=.96, \mathrm{TLI}=.94$, and RMSEA $=.06$. All item-factor loadings were significant ( $p<.001$ ), and ranged from .61 to .87 (other oriented meaning), .50 to .83 (personal meaning), and .56 to .73 (active engagement). The second-order factor loadings were .76 (other-oriented meaning), .82 (active engagement), and .86 (personal meaning). This suggested that the 15 items can be represented by three factors and the three factors can be represented by a second-order factor of career calling, which demonstrated support for our conceptualization of multi-dimensional career calling in this age group.

Construct Validity. To evaluate further the construct validity of the scale, we correlated scores from the career calling scale with scores of existing measures to test convergent, discriminant, and concurrent validity. First, we expected that our scale, which reflects setting, committing to, and pursuing strong, important, and meaningful career goals (i.e., career calling) would be associated positively with the presence of a calling scale (Dik et al., 2012), as these measures have overlapping content. Second, as future oriented pursuit of a career calling reflects having identified a career path, we expected that our scale would be 
associated negatively with the search for a calling scale. This association has been found previously (Duffy \& Sedlacek, 2007). Third, as having a career calling reflects having made a choice about a particular career direction, we expected career calling to be associated negatively with career indecision, as previously found (Duffy \& Sedlacek, 2007; Germeijs \& De Boeck, 2002). Finally, we expected that career calling would be associated positively with subjective well-being (operationalized as judgement of one’s life satisfaction). This association between having settled on a goal and well-being is consistent with goal-setting theory (Locke \& Latham, 1990) and has been found consistently in the career literature (e.g., Duffy \& Sedlacek, 2010; Hirschi, 2009).

Participants who had not completed the career calling scale and/or had completed less than $40 \%$ of the whole survey were excluded. The remaining sample $(N=435)$ contained 3.49\% missing values (53 cases), which were missing completely at random: Little’s MCAR test: $\chi^{2}(31, N=435)=21.89, p=.89$. These data were replaced using the multiple imputation tool available in SPSS 21. The analyses were conducted on these data, while the original data were used to calculate summary statistics (see Table 2).

As seen in Table 2, all correlations were in the predicted direction, providing initial support for the construct validity of the career calling scale. Specifically, we found moderate, positive correlations between career calling and the presence of a calling (full scale $r=.56$; subscale range $=.45$ to .50 ), demonstrating that these scales shared common variance (i.e., calling), while not measuring the exact same thing. There were weak, negative correlations with the search for a calling subscale (full scale $r=-.26$; subscale range $=-.09$ to -.38 ), demonstrating that those higher on career calling were also less likely to report searching for a direction. Similarly, we found moderate, negative associations with career indecision (full scale $r=-.57$; subscale range $=-.33$ to -.50 ), demonstrating that individuals with higher career calling also reported being less indecisive in regards to career choice. Finally, there 
were weak but significant positive correlations with life satisfaction (full scale $r=.18$; subscale range $=.14$ to .17 ), demonstrating that when young adults have a stronger career calling they also report higher levels of satisfaction.

\section{Discussion}

In Study 2, we confirmed the factor structure of the 15-item scale identified in Study 1. As expected, the multidimensional, second-order model indicated a better fit over the unidimensional one. This supports the results of Study 1 and indicates that the three domains are largely independent of one another, but can be represented by a higher-order factor of career calling. This also supports the notion that career calling is a complex, multidimensional construct, which is in line with other multidimensional models of career calling (Dik et al., 2012; Hagmaier \& Abele, 2012). Finally, we demonstrated evidence for the construct validity of the scale by finding expected associations with existing scales of presence of a calling, search for a calling, career indecision, and life satisfaction. The moderate associations between our calling scale and the presence of a calling and career indecision scales were to be expected. Those who scored higher on our scale, which reflects a developing orientation to and a working towards a personally meaningful occupational future, also can be expected to report more presence of a calling and less indecision about their career. The weaker, negative association with search for a calling is consistent with this, as searching for a calling, while related to the calling construct, implies that one desires a calling, but has not yet found it. For life satisfaction, the positive association also was to be expected, as increasing certainty about one's direction can be expected to bring positive benefits (Duffy \& Sedlacek, 2010).

\section{General Discussion}

Career calling is considered to be a developmental and dynamic construct (Weiss et al., 2004). It is especially important for the period encompassing emerging adulthood, as this 
is when young people face the reality of making career decisions, setting career goals, and pursuing them in earnest. Therefore, it is essential to utilize an appropriate measure to assess career calling in this age population, rather than rely on calling scales that were, for example, designed for adults. By identifying the salient career calling domains for young adults, our study advances the theoretical understanding of how career calling is manifested in emerging adults. Additionally, we contribute to the career calling literature by taking an integrative approach to existing conceptualisations and presenting an age-appropriate, psychometrically sound, measure of career calling.

We operationalized career calling as a largely self-set, salient, future-oriented career goal that is personally meaningful, other-oriented, and involves active engagement. In measuring these three independent, but related domains, the scale assesses the main aspects of a developing career calling relevant to young adults who have not yet settled into the fulltime labour force. Personal meaning recognises the importance of a calling that is congruent with one’s identity and values; other-oriented meaning reflects engagement in socially significant activities and goals; while active engagement addresses the striving associated with these motivational orientations. By assessing these three domains, the scale is consistent with the literature on the meaning of work, which stresses the importance of developing and enacting one's calling so that one’s eventual career is experienced as more meaningful, fulfilling, and having wider impact (Berg et al., 2010; Rosso et al., 2010). By tapping the behaviors and strategies associated with a career calling, our scale is consistent with the literature that suggests that the enactment of calling, which goes beyond the simple perceptions of it, is an integral component of the construct (Elangovan et al., 2010; Rosso et al., 2010). This perspective is consistent with other multi-dimensional models, such as that proposed by Duffy and Autin (2013), which suggests that calling involves both "having” and “living” a calling. This brief, 15-item, career calling scale for emerging adults provides a 
practical and convenient multidimensional measure, which will be useful for research purposes, and useful to counselors and practitioners who wish to assess career progress in young people. The scale has excellent reliability for each of the three subscales as well as the full scale, and the initial support for content and construct validity is very promising. In developing the scale, our samples contained disproportionately more university students than students from vocational institutions and non-students. Future research should assess the utility of the measure with more diverse samples of emerging adults to establish generalizability. However, we found trivial associations between the scale and self-reported educational achievement at the end of high school (full scale: $r=-.05$, subscales range: $r=$ .04 to -.06), which suggests that educational achievement is not related to the strength of career calling. Additionally, as our studies were cross-sectional, we were not able to test predictive validity of the new scale. This would be reflected, for example, in studies that demonstrated that higher scores on the scale at one point in time would be associated with more progress in reaching their career goals (e.g., finding a job in line with their calling) and greater well-being in the future. Longitudinal studies are also needed to demonstrate the stability of the new scale over time; for example, by assessing test-retest reliability.

\section{Conclusions and Future Directions}

Experiencing meaning and purpose regarding one’s future career (i.e., career calling) is an important but under-studied construct (Dik \& Steger, 2008), which is associated with the development of self-regulatory behaviors (Elangovan et al., 2010), better individual wellbeing (Hall \& Chandler, 2005), and one’s career development; although less desirable associations of a career calling, such as feeling a sense of duty, sacrifice in one's work, and a narrow career vision, have also been noted (Bunderson \& Thompson, 2009; Dobrow \& TostiKharas, 2012). We anticipate that access to an age-appropriate measure will stimulate future research into career calling in emerging adults and add to the focus that already exists on 
career calling in adults. Future research might investigate the interplay between setting strong, meaningful career goals and self-regulatory behaviors and strategies, and the effect this has on important career outcomes, such as career progress and career-related well-being. Literature and research also suggests that goal pursuit and life satisfaction is affected by personal and environmental factors (Duffy et al., 2012; Locke \& Latham, 1990). Thus, examining the role of personal (e.g., career adaptability) and contextual factors (e.g., family background) on goal progress and satisfaction has the potential to shed light on the doubleedged nature of career calling. Additionally, there has been little work examining variables that facilitate career calling development, the understanding of which is critical if adolescents and emerging adults are to be assisted in clarifying and developing meaningful career and life futures. These recommendations suggest that a better understanding of career calling and its relationships will depend upon researchers articulating and testing a carefully articulated nomological net of the antecedents, consequences, and correlates of the construct.

Finally, the new calling measure has application in counseling and educational programs that focus on promoting healthy, active, and adaptable career progress in young people before they fully enter the workplace. Assessments at this stage would assist individuals to identify strengths and weaknesses in their career thinking and progress. For those without a strong career calling, identifying and clarifying personal interests, values, and goals could be useful. This, in turn, could motivate active engagement and stimulate decisionmaking, which would help them set meaningful career goals, contribute to developing a stronger career identity, and lead them to experience greater well-being. 


\section{References}

Amabile, T. M., Hill, K. G., Hennessey, B. A., \& Tighe, E. M. (1994). The Work Preference Inventory: Assessing intrinsic and extrinsic motivational orientations. Journal of Personality \& Social Psychology, 66, 950-967. Retrieved from http://www.ovidsp.ovid.com

Arnett, J. J. (2000). Emerging adulthood: A theory of development from the late teens through the twenties. American Psychologist, 55, 469-480. doi:10.1037/0003066X.55.5.469

Bandura, A. (1991). Social cognitive theory of self-regulation. Organizational Behavior and Human Decision Processes, 50, 248-287. doi:10.1016/0749-5978(91)90022-L

Bellah, R. N., Madsen, R., Sullivan, W. M., Swidler, A., \& Tipton, S. M. (1985). Habits of the heart. New York: Harper \& Row.

Berg, J. M., Grant, A. M., \& Johnson, V. (2010). When callings are calling: Crafting work and leisure in pursuit of unanswered occupational callings. Organization Science, 21, 973-994. doi:10.1287/orsc.1090.0497

Bunderson, J. S., \& Thompson, J. A. (2009). The call of the wild: Zookeepers, callings, and the double-edged sword of deeply meaningful work. Administrative Science Quarterly, 54, 32-57. doi:10.2189/asqu.2009.54.1.32

Burges, N. J., Manuel, R. S., Duffy, R. D. (2013). Speciality interests and career calling to medicine among first-year medical students. Perspectives on Medical Education, 2, 14-17. doi:10.1007/s40037-012-0037-9

Cardador, M. T., \& Caza, B. B. (2012). Relational and identity perspectives on healthy pursuit of callings. Journal of Career Assessment, 20, 338-353. doi:10.1177/1069072711436162

Colozzi, E. A., \& Colozzi, L. C. (2000). College students' callings and careers: An integrated 
values-oriented perspective. In D. A. Luzzo (Ed.), Career counselling of college students: An empirical guide to strategies that work (pp. 63-91). Washington, DC: American Psychological Association. doi:10.1037/10362-004

Costello, A. B., \& Osborne, J. W. (2005). Best practices in exploratory factor analysis: Four recommendations for getting the most from your analysis. Practical Assessment, Research \& Evaluation, 10, 1-9. Retrieved from http://www.pareonline.net Csikszentmihalyi, M. (1990). Flow: The psychology of optimal experience. New York: Harper \& Row.

Dalton, J. C. (2001). Career and calling: Finding a place for the spirit in work and community. New Directions for Student Services, 95, 17-25. doi:10.1002/ss.19

Dawis, R. V. (2000). Scale construction and psychometric considerations. In H. E. A. Tinsley \& S. D. Brown (Eds.), Handbook of applied multivariate statistics and mathematical modeling (pp. 65-94). San Diego, CA: Academic Press.

Diemer, M. A., \& Blustein, D. L. (2007). Vocational hope and vocational identity: Urban adolescents' career development. Journal of Career Assessment, 15, 98-118. doi:10.1177/1069072706294528

Diener, E., Emmons, R. A., Larsen, R. J., \& Griffin, S. (1985). The satisfaction with life scale. Journal of Personality Assessment, 49, 71-75. doi:10.1207/s15327752jpa4901_13

Dik, B. J., \& Duffy, R. D. (2009). Calling and vocation at work. The Counseling Psychologist, 37, 424-450. doi:10.1177/0011000008316430

Dik, B. J., Eldridge, B. M., Steger, M. F., \& Duffy, R. D. (2012). Development and validation of the Calling and Vocation Questionnaire (CVQ) and Brief Calling Scale (BCS). Journal of Career Assessment, 20, 242-263. doi:10.1177/1069072711434410

Dik, B. J., Sargent, A. M., \& Steger, M. F. (2008). Career development strivings: Assessing 
goals and motivation in career decision-making and planning. Journal of Career Development, 35, 23-41. doi:10.1177/0894845308317934

Dik, B. J., \& Steger, M. F. (2008). Randomised trial of a calling-infused career workshop incorporating counselor self-disclosure. Journal of Vocational Behavior, 73, 203-211. doi:10.1016/j.jvb.2008.04.001

Dobrow, S. (2004). Extreme subjective career success: A new integrated view of having a calling. Academy of Management Conference Best Paper Proceedings, Philadelphia. Retrieved from http://www.bnet.fordham.edu/dobrow/Papers.html

Dobrow, S. (2007). The development of calling: A longitudinal study of musicians. Academy of Management Conference, Philadelphia. Retrieved from http://www.bnet.fordham.edu/dobrow/Papers.htmlDobrow, S. (2013). The dynamics of calling: A longitudinal study of musicians. Journal of Organizational Behavior, 34, 431 - 452. doi:10.1002/job.1808

Dobrow, S. R., \& Tosti-Kharas, J. (2011). Calling: The development of a scale measure. Personnel Psychology, 64, 1001-1049. doi:10.1111/j.1744-6570.2011.01234.x

Dobrow, S. R., \& Tosti-Kharas, J. (2012). Listen to your heart? Calling and receptivity to career advice. Journal of Career Assessment, 20, 264-280. doi:10.1177/1069072711434412

Duffy, R. D., Allan, B. A., \& Bott, E. M. (2012). Calling and life satisfaction among undergraduate students: Investigating mediators and moderators. Journal of Happiness Studies, 13, 469-479. doi:10.1007/s10902-011-9274-6

Duffy, R. D., \& Autin, K. L. (2013). Disentangling the link between perceiving a calling and living a calling. Journal of Counseling Psychology, 60, 219-227. doi:10.1037/a0031934 
Duffy, R. D., Allan, B. A., \& Dik, B. J. (2011). The presence of a calling and academic satisfaction: Examining potential mediators. Journal of Vocational Behavior, 79, 7480. doi:10.1016/j.jvb.2010.11.001

Duffy, R. D., Bott, E. M., Allan, B. A., Torrey, C. L., \& Dik, B. J. (2012). Perceiving a calling, living a calling, and job satisfaction: Testing a moderated, multiple mediator model. Journal of Counseling Psychology, 59, 50-59. doi:10.1002/j.21610045.2009.tb00171.x

Duffy, R. D., \& Dik, B. J. (2013). Research on calling: What have we learned and where are we going? Journal of Vocational Behavior, 83, 428-436. doi:org/10.1016/j.jvb.2013.06.006

Duffy, R. D., Manuel, R. S., Borges, N. J., \& Bott, E. M. (2011). Calling, vocational development, and well-being: A longitudinal study of medical students. Journal of Vocational Behavior, 33, 210 - 223. doi:10.1016/j.jvb.2011.03.023

Duffy, R. D., \& Sedlacek, W. E. (2007). The presence of and search for a calling: Connections to career development. Journal of Vocational Behavior, 70, 590-601. doi:10.1016/j.jvb.2007.03.007

Duffy, R. D., \& Sedlacek, W. E. (2010). The salience of a career calling among college students: Exploring group differences and links to religiousness, life meaning, and life satisfaction. The Career Development Quarterly, 59, 27-41. Retrieved from http://search.proquest.com

Elangovan, A. R., Pinder, C. C., \& McLean, M. (2010). Callings and organizational behavior. Journal of Vocational Behavior, 76, 428-440.

doi:10.1016/j.jvb.2009.10.009 
Germeijs, V., \& De Boeck, P. (2002). A measurement scale for indecisiveness and its relationship to career indecision and other types of indecision. European Journal of Psychological Assessment, 18, 113-122. doi:10.1027//1015-5759.18.2.113

Germeijs, V., Verschueren, K., \& Soenens, B. (2006). Indecisiveness and high school students’ career decision-making process: Longitudinal associations and the mediational role of anxiety. Journal of Counseling Psychology, 53, 397-410. doi:10.1037/0022-0167.53.4.397

Greenhaus, J. H. (1971). An investigation of the role of career salience in vocational behavior. Journal of Vocational Behavior, 1, 209-216. doi:10.1016/00018791(71)90022-4

Hagmaier, T., \& Abele, A. E. (2012). The multidimensionality of calling: Conceptualisation, measurement and a bicultural perspective. Journal of Vocational Behavior, 81, 39-51. doi:10.1016/j.jvb.2012.04.001

Hair, J. F., Black, W. C., Babin, B. J., Anderson, R. E. (2010). Multivariate data analysis. A global perspective. $\left(7^{\text {th }}\right.$ ed.). New Jersey, NJ: Prentice Hall.

Hall, D. T., \& Chandler, D. E. (2005). Psychological success: When the career is a calling. Journal of Organizational Behavior, 26, 155-176. doi:10.1002/job.301

Hardy, L. (1990). The fabric of this world: Inquiries into calling, career choice, and the design of human work. Grand Rapids, Mich.: William B. Eerdmans Publishing Company.

Havighurst, R. J. (1953/1961). Human development and education. New York, US: Longmans, Green and Co.

Hernandez, E. F., Foley, P. F., \& Beitin, B. K. (2011). Hearing the call: A phenomenological study of religion in career choice. Journal of Career Development, 38, 62-88. doi:10.1177/0894845309358889 
Hinkin, T. R. (1998). A brief tutorial on the development of measures for the use in survey questionnaires. Organizational Research Methods, 1, 104-121. doi:10.1177/109442819800100106

Hirschi, A. (2009). Career adaptability development in adolescence: Multiple predictors and effect on sense of power and life satisfaction. Journal of Vocational Behavior, 74, 145-155. doi:10.1016/j.jvb.2009.01.002

Hirschi, A. (2011). Callings in career: A typological approach to essential and optional components. Journal of Vocational Behavior, 79, 60-73. doi:10.1016/j.jvb.2010.11.002

Hirschi, A., \& Hermann, A. (2013). Calling and career preparation: Investigating developmental patterns and temporal precedence. Journal of Vocational nehavior, 83, 51-60. doi:10.1016/j.jvb.2013.02.008

Hunter, I., Dik, B. J., \& Banning, J. H. (2010). College students' perceptions of calling in work and life: A qualitative analysis. Journal of Vocational Behavior, 76, 178-186. doi:10.1016/j.jvb.2009.10.008

Kahn, W. A. (1990). Psychological conditions of personal engagement and disengagement at work. The Academy of Management Journal, 33, 692-724. Retrieved from http://www.jstor.org

Locke, E. A., \& Latham, G. P. (1990). A theory of goal setting and task performance. Englewood Cliffs, NJ: Prentice Hall.

Lord, R. G., Diefendorff, J. M., Schmidt, A. M., \& Hall, R. J. (2010). Self-regulation at work. Annual Review of Psychology, 61, 543-568. doi:10.1146/annurev.psych.093008.100314Loscocco, K. A. (1989). The interplay of personal and job characteristics in determining work commitment. Social Science Research, 18, 370-394. doi:10.1016/0049-089x(89)90013-6 
Lynn, M. R. (1985). Determination and quantification of content validity. Nursing Research, 35, 382-386. doi:10.1097/00006199-198611000-00017

Novak, M. (1996). Business as a calling: Work and the examined life. New York, US: The Free Press.

Nurmi, J. E. (1993). Adolescent development in an age-graded context: The role of personal beliefs, goals, and strategies in the tackling of developmental tasks and standards. International Journal of Behavioral Development, 16, 169-189. doi:10.1177/016502549301600205

O’Connor, B. (2000). SPSS and SAS programs for determining the number of components using parallel analysis and Velicer’s MAP test. Behavior Research Methods, 32, 396402. doi:10.3758/bf03200807

Rosso, B. D., Dekas, K. H., \& Wrzesniewski, A. (2010). On the meaning of work: A theoretical integration and review. Research in Organizational Behavior, 30, 91-127. doi:10.1016/j.riob.2010.09.001

Sharf, R. S. (2006). Applying career development theory to counseling. Southbank, Australia: Thomson Wadsworth.

Shulman, S., \& Nurmi, J.-E. (2010). Dynamics of goal pursuit and personality make-up among emerging adults: Typology, change over time, and adaptation. In S. Shulman \& J.-E. Nurmi (Eds.), The role of goals in navigating individual lives during emerging adulthood (pp. 57-70). San Francisco, CA: Wiley Periodicals.

Steger, M. F., Pickering, N. K., Shin, J. Y., \& Dik, B. J. (2010). Calling in work: Secular or sacred? Journal of Career Assessment, 18, 82-96. doi:10.1177/1069072709350905

Vallerand, R. J., Blanchard, C., Mageau, G. A., Koestner, R., Ratelle, C., Leonard, M., \& Gagne, M. (2003). Les passions de l'Ame: On obsessive and harmonious passion. Journal of Personality and Social Psychology, 85, 756-767. doi:10.1037/0022- 
3514.85.4.756

Vogt, D. S., King, D. W., \& King, L. A. (2004). Focus groups in psychological assessment: Enhancing content validity by consulting members of the target population.

Psychological Assessment, 16, 231-243. doi:10.1037/1040-3590.16.3.231

Weiss, J. W., Skelley, M. F., Haughey, J. C., \& Hall, D. T. (2004). Calling, new careers and spirituality: A reflective perspective for organizational leaders and professionals. Research in Ethical Issues in Organizations, 5, 175-201. doi:10.1016/S15292096(03)05009-0

Wrzesniewski, A., Dekas, K., \& Rosso, B. (2009). Callings. In S. Lopez \& A. Beauchamp (Eds.), Encyclopedia of positive psychology (pp. 115-118). Oxford, UK: Blackwell.

Wrzesniewski, A. (2012). Callings. In K. S. Cameron \& G. M. Spreitzer (Eds.), The Oxford handbook of positive organizational scholarship (pp. 45-55). Oxford, UK: Oxford University Press.

Wrzesniewski, A., McCauley, C., Rozin, P., \& Schwartz, B. (1997). Jobs, careers, and callings: People's relations to their work. Journal of Research in Personality, 31, 2133. doi:10.1006/jrpe.1997.2162 
Table 1

Factor Loadings for the Career Calling Scale for Emerging Adults; Sample $1(N=345)$

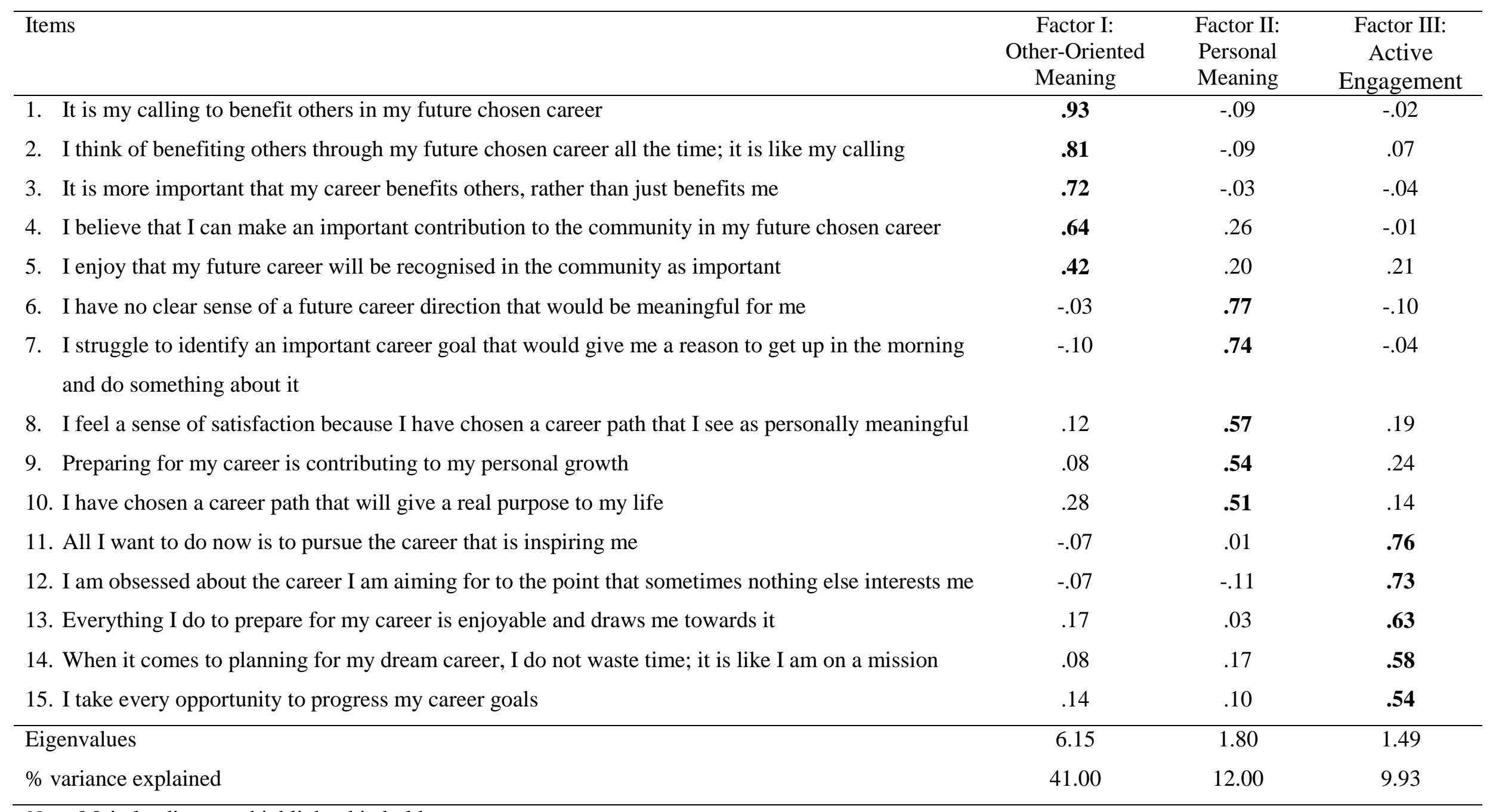

Note. Main loadings are highlighted in bold. 
Table 2

Summary Data and Bivariate Correlations for Variables used in Study $2(N=435)$

\begin{tabular}{|c|c|c|c|c|c|c|c|c|c|c|c|}
\hline Variables & $M$ & $S D$ & Range & 1 & 2 & 3 & 4 & 5 & 6 & 7 & 8 \\
\hline 1. Career calling: Full scale & 68.48 & 10.46 & $25-90$ & - & $.83 * * *$ & $.82 * * *$ & $.82 * * *$ & $.56 * * *$ & $-.26 * * *$ & $-.57 * * *$ & $.18^{* *}$ \\
\hline 2. Career calling subscale: Other-oriented meaning & 22.80 & 4.39 & $5-30$ & & - & $.54 * * *$ & $.50 * * *$ & $.50 * * *$ & -.09 & $-.33 * * *$ & $.14^{* *}$ \\
\hline 3. Career calling subscale: Personal meaning & 24.87 & 4.02 & $6-30$ & & & - & $.53^{* * *}$ & $.48 * * *$ & $-.38 * * *$ & $-.59 * * *$ & $.14^{* *}$ \\
\hline 4. Career calling subscale: Active engagement & 20.81 & 4.28 & $7-30$ & & & & - & $.41 * * *$ & $-.19 * * *$ & $-.50 * * *$ & $.17 * *$ \\
\hline 5. Presence of a calling & 8.46 & 2.49 & $2-12$ & & & & & - & $-.23 * * *$ & $-.46 * * *$ & $.12 *$ \\
\hline 6. Search for a calling & 6.40 & 2.72 & $2-12$ & & & & & & - & $.48 * * *$ & .01 \\
\hline 7. Career indecision & 31.30 & 9.66 & $10-57$ & & & & & & & - & $-.17 * * *$ \\
\hline 8. Life satisfaction & 20.83 & 5.17 & $5-30$ & & & & & & & & - \\
\hline
\end{tabular}

$* p<.05, * * p<.01, * * * p<.05$ 